\title{
The MtrD protein of Neisseria gonorrhoeae is a member of the resistance/nodulation/division protein family constituting part of an efflux system
}

\author{
Kayla E. Hagman, ${ }^{1,2}+$ Claressa E. Lucas, ${ }^{1,2}$ Jacqueline T. Balthazar, ${ }^{1,3}$ \\ Lori Snyder, ${ }^{1,2}$ Matthew Nilles, ${ }^{4}$ Ralph C. Judd ${ }^{5}$ and William M. Shafer ${ }^{1,2,3}$
}

Author for correspondence: William M. Shafer. Tel: +1 404728 7688. Fax: +1 4043292210.

e-mail: wshafer@emory.edu

1,2 Program in Microbiology and Molecular Genetics of the Graduate Division of Biological and Biomedical Sciences ${ }^{1}$ and Dept of Microbiology and Immunology2, Emory University School of Medicine, Atlanta, GA 30322, USA

3 Laboratories of Microbial Pathogenesis, VA Medical Research Service, VA Medical Center (Atlanta) Decatur, GA 30033, USA

4 Department of Microbiology and Immunology, University of Kentucky, Lexington, KY 40536-0084, USA

5 Department of Biological Sciences, University of Montana, Missoula, MT 59182-1002, USA
The mtr (multiple transferable resistance) system of Neisseria gonorrhoeae mediates resistance of gonococci to structurally diverse hydrophobic agents (HAs) through an energy-dependent efflux process. Recently, complete or partial ORFs that encode membrane proteins (MtrC, MtrD, MtrE) forming an efflux pump responsible for removal of HAs from gonococci were identified and appeared to constitute a single transcriptional unit. In this study, the complete nucleotide sequence of the mtrD gene was determined, permitting the characterization of the MtrD protein. The full-length MtrD protein has a predicted molecular mass of nearly $114 \mathrm{kDa}$, putatively containing a 56 amino acid signal peptide. MtrD displays significant amino acid sequence similarity to a family of cytoplasmic membrane proteins, termed resistance/nodulation/ division (RND) proteins, which function as energy-dependent transporters of antibacterial agents and secrete bacterial products to the extracellular fluid. The predicted topology of the MtrD transporter protein revealed 12 potential membrane-spanning domains, which were clustered within the central and Cterminal regions of the primary sequence. Loss of MtrD due to insertional inactivation of the mtrD gene rendered gonococci hypersusceptible to several structurally diverse HAs, including two fatty acids (capric acid and palmitic acid) and a bile salt (cholic acid), but not hydrophilic antibiotics such as ciprofloxacin and streptomycin. Since gonococci often infect mucosal sites rich in toxic fatty acids and bile salts, the expression of the mtr efflux system may promote growth of gonococci under hostile conditions encountered in vivo.

Keywords: Neisseria gonorrboeae, antimicrobial resistance, efflux, transporter, MtrD

\section{INTRODUCTION}

Neisseria gonorrboeae infects mucosal surfaces that are often bathed in antibacterial hydrophobic agents (HAs) such as fatty acids and bile salts (McFarland et al., 1983; Morse et al., 1982). The capacity of gonococci to infect sites rich in HAs has been associated with the $m t r$

tPresent address: Department of Microbiology and Immunology, University of Texas Southwestern Medical School, Dallas, TX 75235, USA.

Abbreviations: HA, hydrophobic agent; RND, resistance/nodulation/ division; for other abbreviations see footnote to Table 1.

The GenBank accession number for the $m t r D$ nucleotide sequence reported in this paper is U60099. (multiple transferable resistance) system (Morse et al., 1982; Shafer et al., 1984) since $m$ tr confers broadspectrum resistance to hydrophobic drugs, dyes and detergents (Guymon \& Sparling, 1975; Maness \& Sparling; 1973; Shafer et al., 1984). Strains expressing HA-resistance $\left(\mathrm{HA}^{\mathbf{R}}\right)$ due to $m t r$ are frequently isolated from patients with rectal infections (Morse et al., 1982) as well as uncomplicated urogenital infections (Urdez \& Shafer, unpublished observations).

The $m t r$ system was originally proposed to regulate the permeability barrier of the gonococcal cell envelope to HAs (Guymon \& Sparling, 1975), but more recent genetic (Hagman et al., 1995; Pan \& Spratt, 1994) and physiological (Lucas et al., 1995) studies demonstrated 


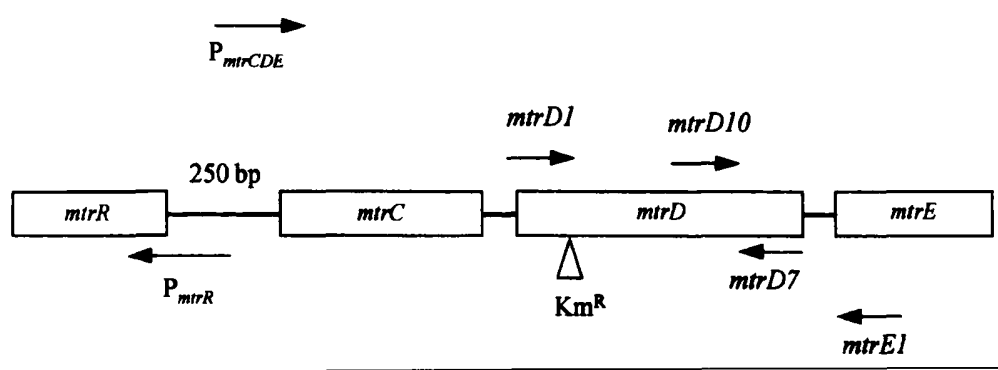

Fig. 1. Genetic organization of the $m t r$ efflux operon in $N$. gonorrhoeae. The divergent $m$ trR and $m \operatorname{trCDE}$ genes (Hagman et al., 1995) are shown, together with the intervening region containing their divergent promoters $\left(\mathbf{P}_{\text {mtre }}\right.$ and $\mathbf{P}_{\text {mtrCDE, }}$ as described by Hagman \& Shafer, 1995) and the approximate sites of annealing of the major oligonucleotide primers (mtrD1. $m$ trD7, mtrD10 and mtrE1) described in the text. that $m t r$ functions as an energy-dependent efflux pump that removes HAs by a mechanism requiring the proton motive force. Thus, the mir efflux system resembles other bacterial efflux pumps, notably the mexABoprMencoded system of Pseudomonas aeruginosa (Li et al., 1995 ; Poole et al., 1993a,b) and the acrAB- and acrEFencoded systems of Escherichia coli (Ma et al., 1994); acr $A B$ was previously termed acrEF (Ma et al., 1993), while acrEF was previously termed envCD (Klein et al., 1991). Nucleotide sequencing studies (Hagman et al., 1995; Pan \& Spratt, 1994) revealed that the mtr gene complex is composed of a regulatory gene (mtrR) encoding a transcriptional repressor (MtrR), and three genes encoding membrane proteins (MtrC, MtrD and MtrE) that form an efflux pump (Lucas et al., 1995).

The $m t r C D E$ gene complex in gonococci represents a single transcriptional unit that is located $250 \mathrm{bp}$ upstream and transcribed divergently from the $m t r R$ gene (Fig. 1). The entire $m t r C$ gene from strain FA19 was previously identified (Hagman et al., 1995) in a cloned $2.57 \mathrm{~kb}$ DraI fragment that also contained partial ORFs for $m t r R$ and $m t r D$; the translational start codon for $m t r D$ was located 11 nucleotides downstream from the $m t r C$ translational stop codon. A second plasmid construct obtained with DNA from a clinical isolate contained the remainder of the $m t r D$ gene and the start of a third ORF. This third ORF was termed $m t r E$ and the limited amino acid sequence that could be deduced suggested that its product would be similar to the OprM outer-membrane lipoprotein of $P$. aeruginosa ( $\mathrm{Li}$ et al., 1995) that is required for efflux of antibiotics (Poole et al., 1993a,b) from this pathogen.

Homology studies (Hagman et al., 1995) of the deduced amino acid sequence for MtrC revealed a consensus fatty acid acylation site at the $\mathrm{N}$-terminus of the mature protein and a high degree of similarity to a growing list of bacterial proteins termed membrane fusion proteins (Saier et al., 1994). The partially characterized (Hagman et al., 1995) MtrD protein consists of 243 amino acids that have homology with the N-terminal amino acid sequences of members of the resistance/nodulation/division (RND) family of cytoplasmic membrane proteins (Saier et al., 1994). These RND proteins have been proposed to serve as transporters that interact with a companion membrane fusion protein for energydependent efflux of antibacterial compounds (Ma et al., 1994; Saier et al., 1994). To gain a better understanding of the structural components of the $m t r$ efflux pump, we determined the complete nucleotide sequence of the entire $m t r D$ gene and constructed transformants of $N$. gonorrboeae strain FA19 bearing an insertionally inactivated $m$ tr $D$ gene.

\section{METHODS}

Strains of $\boldsymbol{N}$. gonorrhoeae employed and growth conditions. The gonococcal strains employed in this investigation are given in Table 1. Strain FA19 (Sparling et al., 1975) is the parental strain of transformant strains KH8, KH12, KH14, KH15 and LD1. Strains KH8, KH12 and KH15 were constructed previously (Hagman et al., 1995), while strain LD1 was constructed by transformation using donor DNA from strain KH14 to transform strain KH15 (see below). These strains were grown on GCB agar with defined supplements at $37^{\circ} \mathrm{C}$ under $3.8 \%(\mathrm{v} / \mathrm{v}) \mathrm{CO}_{2}$ or in GC broth as previously described (Shafer et al., 1984). For transformation experiments, piliated transparent colony types were used (Sparling et al., 1975), but nonpiliated transparent variants were used to determine susceptibility to antimicrobial agents.

Antimicrobial agent susceptibility testing. The susceptibility of gonococcal strains to capric acid (CA), cholic acid (CHA), ciprofloxacin (CP), crystal violet (CV), erythromycin (ERY), palmitic acid (PA), streptomycin (STR) and Triton X-100 (TX-100) was determined by the agar plating method described by Shafer et al. (1984). All of these compounds were purchased from Sigma except for CP, which was obtained from the Pharmacy Service of the Atlanta VA Medical Center. CA, CHA, ERY and PA were dissolved in $100 \%(\mathrm{v} / \mathrm{v})$ ethanol.

PCR amplification and nucleotide sequencing of the $m$ trD gene. Chromosomal DNA from strain FA19 was prepared by the method of McAllister \& Stephens (1993). Oligonucleotide primers $m t r D 1$ (5'-CGGCATCTGAAGCCAAACCTGC-3') and $m t r E 1$ (5'-GATGGAAGAAACCGATGTGTCG-3') were used in PCR amplification of the $m t r D$ sequence under conditions described previously (Hagman et al., 1995). Oligonucleotides $m t r D 1$ and $m t r E 1$ anneal 24 nucleotides upstream of the $m t r D$ translational start codon and 171 nucleotides downstream from the $m t r D$ translational stop codon, respectively (Fig. 1). DNA sequencing was conducted on both strands using mtrD1, mtrE1 and additional oligonucleotide primers, which were prepared based on determined sequences by the cycle sequencing method (Hagman et al., 1995) that employs AmpliTaq DNA polymerase; primers were labelled with $\left[\gamma-{ }^{32} \mathrm{P}\right]$ ATP (NEN DuPont).

Nucleotide and amino acid sequence analysis was performed using DNAStar. Predicted amino acid homologies were determined after searching the GBTRANS/SWISS-PROT/ EMBL databases using the DNAStar Proscan program. The signal peptide of MtrD was identified using the PSORT program which is available on the World Wide Web 
Table 1. Susceptibility of gonococci to antimicrobial agents

\begin{tabular}{|c|c|c|c|c|c|c|c|c|c|}
\hline \multirow[t]{2}{*}{ Strain } & \multirow[t]{2}{*}{ Genotype } & \multicolumn{8}{|c|}{$\operatorname{MIC}\left(\mu \mathrm{g} \mathrm{ml}^{-1}\right)$ of :* } \\
\hline & & CA & PA & CHA & $\mathrm{CV}$ & TX-100 & ERY & STR & $\mathrm{CP}$ \\
\hline FA19 & Wild-type & 300 & 200 & 300 & $2 \cdot 5$ & 100 & 0.25 & 25 & 0.002 \\
\hline KH8 & $\begin{array}{c}\text { As FA19 but } \\
m t r R-95\end{array}$ & ND & ND & ND & 10 & $>16000$ & $2 \cdot 0$ & 25 & 0.002 \\
\hline KH12 & $\begin{array}{l}\text { As FA19 but } \\
m t r C:: \mathrm{Km}^{R}\end{array}$ & 25 & 25 & 150 & $<1 \cdot 25$ & 25 & 0.06 & 25 & 0.002 \\
\hline KH14 & $\begin{array}{l}\text { As FA19 but } \\
m t r D:: \mathrm{Km}^{\mathrm{R}}\end{array}$ & $12 \cdot 5$ & 25 & 100 & $<1 \cdot 25$ & 25 & 0.06 & 25 & 0.002 \\
\hline KH15 & $\begin{array}{l}\text { As FA19 but } \\
\text { mtrR-171 }\end{array}$ & $>500$ & 800 & $>500$ & 10 & $>16000$ & $2 \cdot 0$ & 25 & 0.002 \\
\hline LD1 & $\begin{array}{l}\text { As KH15 but } \\
m t r D:: \mathrm{Km}^{\mathrm{R}}\end{array}$ & 25 & 25 & 100 & ND & 25 & 0.06 & ND & 0.002 \\
\hline
\end{tabular}

ND, Not determined.

*CA, capric acid; PA, palmitic acid; CHA, cholic acid; CV, crystal violet; TX-100, Triton X-100; ERY, erythromycin; STR, streptomycin; CP, ciprofloxacin.

(http://www.PSORT.nibb.oc.jp). A predicted topology model was developed for MtrD using the algorithm of von Heijne $(1989,1992)$ as implemented by the TopPred II program (Claros \& von Heijne, 1994). A hydrophobicity profile was created using the GcH1 scale (von Heinje, 1992) with the window size set to 21 amino acids.

Insertional inactivation of the mtrD gene. A 758 bp region representing the $5^{\prime}$-end of the $m t r D$ gene was prepared by PCR amplification of FA19 chromosomal DNA. The PCR reaction employed oligonucleotide primers $m t r D 1$ (see above) and $m t r D 2$. Primer $m t r D 2 \quad\left(5^{\prime}\right.$-GCCGT ACCCAACTGCCCTT GC-3') anneals 712 nucleotides downstream from the $m t r D$ translational start codon. The $758 \mathrm{bp}$ product contained a unique HindIII site 328 nucleotides downstream of the translational start codon that was used for insertional inactivation of the $m t r D$ gene. This $m t r D$ sequence was cloned into pCR-Script (Stratagene) following the manufacturer's directions. The cloned $m t r D$ fragment was removed from the pCR-Script vector by digesting with EcoRI and NotI, subjected to agarose gel electrophoresis and subsequently purified using Qiaex beads according to manufacturer's directions (Qiagen). The purified $m t r D$ fragment was cloned into EcoRI/NotI-digested pBS $\Delta \mathrm{H} 3$, which is pBluescript lacking the unique HindIII site; pBS $\Delta \mathrm{H} 3$ was created by digesting pBluescript with HindIII, filling in the overhangs with Klenow fragment (Boehringer Mannheim) and ligating the blunt ends. Once the $m t r D$ fragment had been cloned into pBS $\Delta \mathrm{H} 3$, the construct (pBSmtrD1) was digested with HindIII and the kanamycin resistance $\left(\mathrm{Km}^{\mathrm{R}}\right)$ cassette from $\mathrm{pH} 45 \Omega \mathrm{Km}^{\mathrm{R}}$ (Prentki \& Krisch, 1984) was inserted. E. coli strain XL1-Blue was transformed with the construct and transformants resistant to ampicillin $\left(100 \mu \mathrm{g} \mathrm{m}^{-1}\right)$ and kanamycin $\left(50 \mu \mathrm{g} \mathrm{ml}^{-1}\right)$ were selected. Oligonucleotide primers $m t r D 1$ and $m t r D 2$ were used in PCR reactions to verify insertion of the $\mathrm{Km}^{\mathrm{R}}$ cassette in the $m t r D$ gene (Fig. 1) of selected transformants and a representative PCR product was used to transform FA19 to $\mathrm{Km}^{\mathrm{R}}\left(50 \mu \mathrm{g} \mathrm{m}^{-1}\right)$. DNA from a representative transformant (strain KH14) was subjected to PCR-amplification using oligonucleotide primers $m t r D 1$ and $m t r D 2$ to verify insertional inactivation of $m t r D$ and for transformation experiments using strain KH15 (FA19 mtrR-171) as the recipient.
PAGE and Western blotting of proteins. Whole-cell lysates were prepared and analysed by SDS-PAGE as described by Laemmli (1970). Gels were stained sequentially with silver and Coomassie Brilliant Blue or electrophoretically blotted to PVDF membranes. Membranes were blocked with Dulbecco's PBS $/ 0.05 \%(\mathrm{v} / \mathrm{v})$ Tween-20. Western blots were probed with a monoclonal antibody to MtrC as described previously (Judd et al., 1991; Hagman et al., 1995) or a rabbit antiserum against a synthetic peptide of MtrD (FNKKFDSWTHGYEGRVA), which corresponds to amino acids 513-529 of the full-length protein. This peptide was synthesized by the University of Montana Molecular Biology Facility and was used to immunize female New Zealand White rabbits using standard protocols. Briefly, $0.25 \mathrm{ml}$ of a $1 \mathrm{mg} \mathrm{ml}^{-1}$ stock peptide solution in complete Freund's adjuvant was injected subcutaneously at two inguinal and two axillary sites, followed by one intramuscular injection of $0.25 \mathrm{ml}$ of the peptide stock solution 1 week later. Intravenous injections followed at 2 week intervals. Prior to the initial injection, pre-bleeds of the rabbits were obtained and sera was subsequently collected after peptide injections at weekly intervals. The anti-MtrD peptide antiserum was pre-absorbed three times with a wholecell Triton X-100 lysate of E. coli XL-1 Blue (Hagman et al., 1995) and clarified by centrifugation prior to use. The antiMtrD peptide antiserum was used at a 1:5 dilution. Antigen-antibody reactions were detected using horseradish peroxidase-conjugated antibodies against mouse IgG or rabbit IgG prepared in goats.

Analysis of $m t r C D$ gene expression. Total RNA was prepared from goncococcal strains by the method of Baker \& Yanofsky (1968). Transcripts corresponding to products of the mtrC, $m t r D$ and $r m p$ genes were detected using a slot-blot hybridization procedure (Hagman \& Shafer, 1995) that employed gene-specific probes. The $r m p$ gene in gonococci is not under MtrR control (Hagman \& Shafer, 1995) and its mRNA serves as an internal control in slot-blot hybridizations. The $m t r C$ and $r m p$ gene probes were described previously (Hagman \& Shafer, 1995). An $m t r D$-specific gene probe was prepared by PCR amplification of chromosomal DNA prepared from strain FA19. This probe was prepared using oligonucleotide primers $m t r D 7$ (5'-ATATACAGGGGAACCACGCCC-3') 
and $m t r D 10$ (5'-AGCATCAACCTGCAAGACCGC-3'). $m t r D 7$ anneals 202 nucleotides from the translational stop codon of $m t r D$, while $m t r D 10$ anneals 1171 nucleotides from the $m t r D$ stop codon (Fig. 1). The 969 bp product that resulted from PCR amplification corresponds to a sequence $1699 \mathrm{bp}$ downstream of the $\mathrm{Km}^{\mathrm{R}}$ cassette insertion in strain KH14 (Fig. 1). DNA probes were labelled with $\left[\alpha^{32} \mathrm{P}\right] \mathrm{dGTP}$ using the Boehringer Mannheim random primer labelling kit as directed by the manufacturer. All conditions used in slot-blot hybridizations were as described previously (Hagman \& Shafer, 1995).

\section{RESULTS AND DISCUSSION}

\section{Sequence analysis and characteristics of MtrD}

The N-terminal 243 amino acids of MtrD were deduced previously by sequencing a cloned DNA fragment from strain FA19 that contained a partial $m t r R$ gene, a complete $m t r C$ gene and a partial $m t r D$ gene (Hagman et al., 1995). The limited amino acid sequence that could be deduced for MtrD suggested that this protein was similar to other bacterial transporter proteins that participate in efflux of antimicrobial agents. To confirm this hypothesis, it was necessary to obtain the complete $m t r D$ gene. Thus, oligonucleotide primers $m t r D 1$ and $m t r E 1$ (Fig. 1) were used to amplify the entire $m t r D$ region from chromosomal DNA of strain FA19. DNA sequencing of the resulting $3.3 \mathrm{~kb}$ PCR product revealed a large ORF (3204 nucleotides) that encodes a 1067 amino acid protein, MtrD (Fig. 2). The first 243 amino acids of the full-length MtrD protein were identical to those predicted earlier by DNA sequencing of the partial $m$ trD gene in pKH9 (Hagman et al., 1995). The fulllength MtrD protein was predicted to have a molecular mass of $113.9 \mathrm{kDa}$ and a $\mathrm{pI}$ of 6.86 . Using the PSORT program, a potential signal I peptidase cleavage site for
MtrD was located between Val-56 and Met-57; removal of the 56 amino acid signal peptide would result in the mature MtrD protein having a molecular mass of 107.9 $\mathrm{kDa}$ and a pI of $6 \cdot 1$; the relatively long signal peptide in MtrD is similar in length to that proposed (Poole $e t$ al., 1993a) for the MexB protein possessed by P. aeruginosa. Alignment of MtrD with MexB of $P$. aeruginosa and AcrB and AcrF of E. coli showed that it is highly similar to these transporter proteins, confirming that it is a member of the RND protein family. MtrD is $49 \%$ identical to MexB (GenBank accession number GBL11616) over 1057 amino acids, $43 \%$ identical to AcrB (GenBank accession number UU00734) over 978 amino acids and $43 \%$ identical to AcrF (GenBank accession number X57948) over 990 amino acids.

\section{Membrane topology of MtrD}

The RND protein family is thought to represent integral cytoplasmic membrane proteins with numerous transmembrane domains that are presumed to facilitate interactions with their respective partner membrane fusion proteins (Saier et al., 1994). The predicted topology of full-length MtrD revealed that it has $12 \alpha$ helical transmembrane segments (Fig. 3). The clustering of these potential membrane-spanning segments within the central and C-terminal regions of $M \operatorname{trD}$ is remarkably similar to that proposed for MexB (Poole et al., 1993a), as well as AcrB (Ma et al., 1993), AcrF (Ma et al., 1994) and AcrD (Nilles \& Bertrand, unpublished observations). The model shown in Fig. 3 can be viewed as consisting of two nearly symmetrical halves, with each having a similar predicted structure. Thus, each half has an initial transmembrane segment (numbered 1-7 in Fig. 3), followed by two large loops (labelled P1

$----,----+----,----+----,----+----,,----+-----,---+----,----+$

1 MAKFFIDRPIFAWVISIFIIAAGIFGIKSLPVSQYPSVAAPTITLHAIYPGASAQVMEGS 60

61 VLSVIERNMNGVEGLDYMSTSADSSGSGSVSLTFTPDTDENLAQVEVQNKLSEVLRTLPA 120

121 TVQQYGVTVSKARSNFLMIVMLSSDVQSTEEMNDYAQRNVVPELQRIEGVGQVRLFGAQR 180

181 AMRIWVDPKKLQNYNLSFADVGSALSAQNIQISAGSIGSLPAVRGQTVTATVTAQGQLGT 240

241 AEEFGNVILRANTDGSNIYLKDVAKVGLGMEDYSSSTRLNGVNTTGMAVMLSNSGNAMAT 300

3010

301 AKAVKERLAVLEKY FPQGMSWKTPYDTSKFVEISIEKVIHTLIEAMVLVFVVMYLFLQNI 360

361 RYTLIPTIVVPISLLGGFAFISYMGMSINVLTMFAMILVIGIVVDDAIVVVENVERIMAG 420

421 EGLPPKEATKKAMGQISGAVIGITAVLISVFVPLAMFSGAAGNIYKQFALTMASSIAFSA 480

481 FLALTLTPALCATMLKTIPKGHHEEKKGFFGWFNKKFDSWTHGYEGRVAKVLRKTFRMMV 540

541 VYIGLAVVGVFLFMRLPTSFLPTEDQGFVMVSVQLPAGATKERTDATLAQVTQLAKSIPE 600

601 IENIITVSGFSFSGSGONMAMGFAIFKDWNERTASGSDAVAVAGKLTGMMMGTLKDGFGI 660

661 AVVPPPILELGNGSGLSINLQDRNNTGHTGIAGEGNELIQKMRASGLFDPSTVRAGGLED 720

721 SPQLKIDINRAAAAAQG ISFADIRTALASALSSSYVSDFPNQGRLQRVMVQADEDARMQP 780

781 ADILNLTVPNKSGVAVPLSTIATVSWENGTEQSVRFNGYPSMKLSASPATGVSTGQAMEA 840

841 VQKMVDELGGGYSFEWGGQSSEEAKGGSQTLILYGLAVAAVFLVLAALYESWSIPLAVIL 900 $----,----+----,----+----,----+----,----+----,----+----,----+$

901 VIPLGLIGAAAGVTGRNLFEGLLGSVPSFANDIYFQVGFVTVMGLSAKNAIIIIEFAKDL 960

961 QAQGKSAVEAALEAARLRFRPIIMTSFAFILGVVPLYIAAGASSASQRAIGTTVFWGMLV 1020

1021 GTLLSVFLVPLFYVVVRKFFKETAHEHEMAVRHASKAGITGSDDKQY . 1068

Fig. 2. Amino acid sequence of MtrD. The full-length MtrD protein from $N$. gonorrhoeae strain FA19 is shown in single amino acid letter code. 


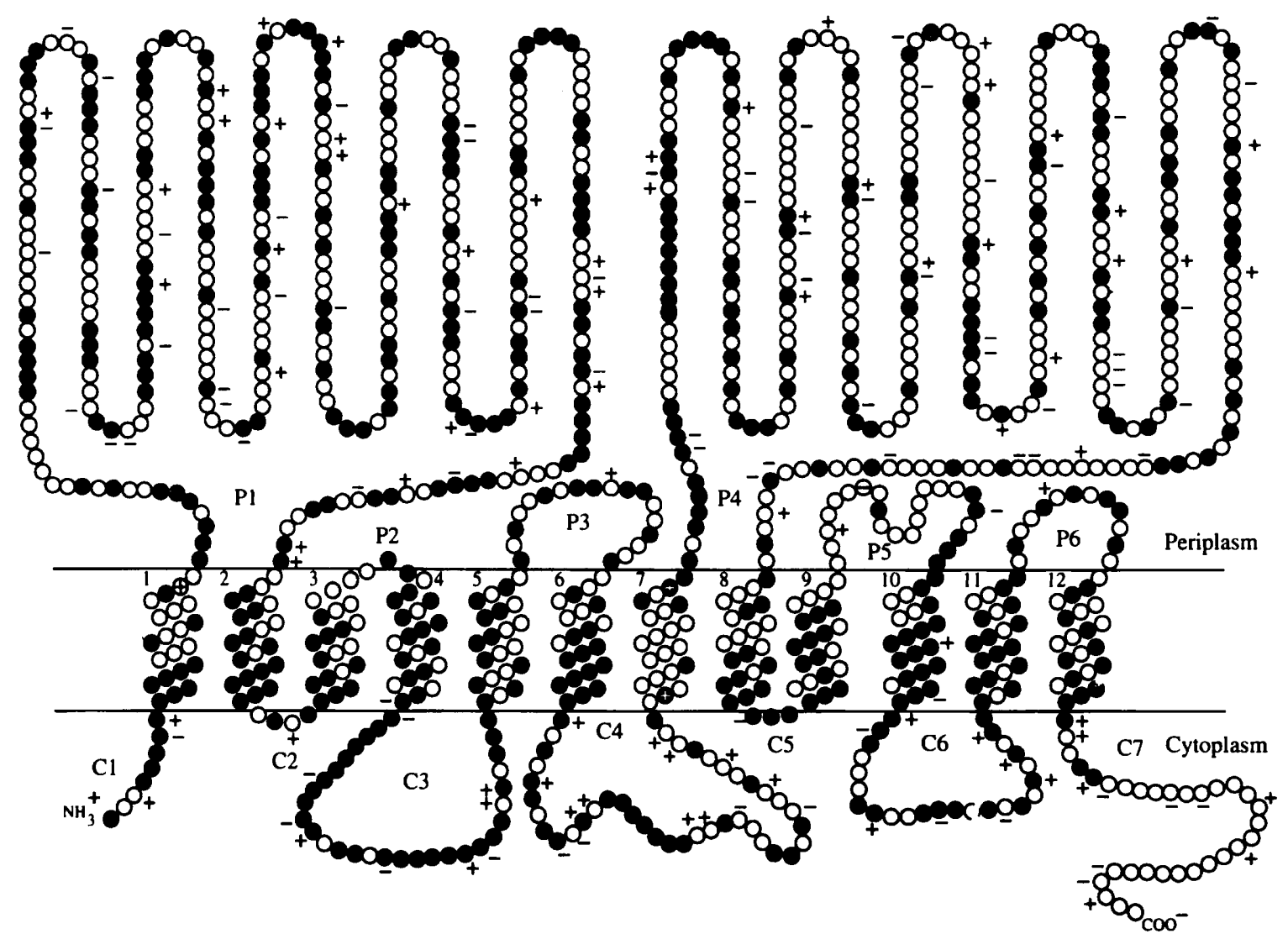

Fig. 3. Topology and potential membrane-spanning domains of MtrD. From the hydrophobicity profile of MtrD, a model was generated by applying the positive-inside rule (von Heijne, 1992) to determine the preferred topology model, which is shown. The 12 transmembrane domains of full-length MtrD are numbered sequentially, 1-12. Periplasmic domains (P1-P6) and cytoplasmic domains (C1-C7) are shown. Pluses indicate the positions of basic amino acids (arginine and lysine), while minuses indicate the positions of acidic amino acids (aspartate and glutamate). Amino acids in MtrD that are identical to two of three similar transporters (MexB, AcrB or AcrF) are shown as filled circles.

and P4 in Fig. 3) that may extend into the periplasm, facilitating interactions with its companion membrane fusion protein, MtrC. Not suprisingly, the topology model for MtrD is similar to models constructed for other homologues in the RND family of transporters, including MexB, AcrB, AcrF and AcrD (Nilles \& Bertrand, unpublished observations). Importantly, the signature sequence of $\mathrm{R}(\mathrm{LIV}) \mathrm{RP}(\mathrm{LIV})_{2} \mathrm{MT}(\mathrm{ATS}) \mathrm{L}$, identified by Saier et al. (1994) as being highly conserved even among distantly related members of the RND family, was found within a likely membrane-spanning region between residues 978 and 987 of full-length MtrD. The near consensus signature sequence in MtrD (RFRPILMTSF) differs from that of AcrF and MexB by two conservative phenylalanine substitutions (positions 979 and 987) for leucines at positions 901 and 909 in $\mathrm{AcrF}$, and 970 and 978 in MexB.

\section{Insertional inactivation of $m$ trD renders gonococci hypersusceptible to HAs}

The wild-type copy of the $m t r D$ gene in strain FA19 (Fig. 1) was replaced with an insertionally inactivated $m t r D$ sequence that contained the $\mathrm{Km}^{\mathrm{R}}$ cassette from
pH45 $\Omega \mathrm{Km}^{\mathrm{R}}$ (Prentki \& Krisch, 1984). Agarose gel electrophoresis of PCR-amplified $m t r D$ products derived from chromosomal DNA preparations of strains FA19 and a representative transformant (strain KH14) confirmed the expected shift-up of the $m t r D$ band in the KH14 PCR product (data not presented). Transformant strain KH14 did not differ significantly from parental strain FA19 in growth rate in GCB broth (data not presented). However, compared to parental strain FA19, strain $\mathrm{KH} 14$ was hypersusceptible to a panel of structurally diverse HAs (CA, CHA, CV, ERY, PA and TX100 ; Table 1), but not hydrophilic antibiotics such as $\mathrm{CP}$ and STR (Table 1). The HA-susceptibility phenotype displayed by strain $\mathrm{KH} 14$ was similar to that of strain $\mathrm{KH} 12$, which bears an insertionally inactivated $m t r C$ gene (Table 1). Moreover, insertional inactivation of the $m t r D$ gene in strain KH15, which bears the $m t r R-171$ mutation that affords high-level $\mathrm{HA}^{\mathbf{R}}$ due to a single bp deletion in the $m t r R$ promoter (Hagman \& Shafer, 1995; Hagman et al., 1995), also resulted in hypersusceptibility of gonococci to HAs (see strain LD1 in Table 1). We recognized that insertional inactivation of $m t r D$ by the $\mathrm{Km}^{\mathrm{R}}$ cassette from $\mathrm{pH} 45 \Omega \mathrm{Km}^{\mathrm{R}}$ would also result in loss of expression of the tandemly linked $m t r E$ 


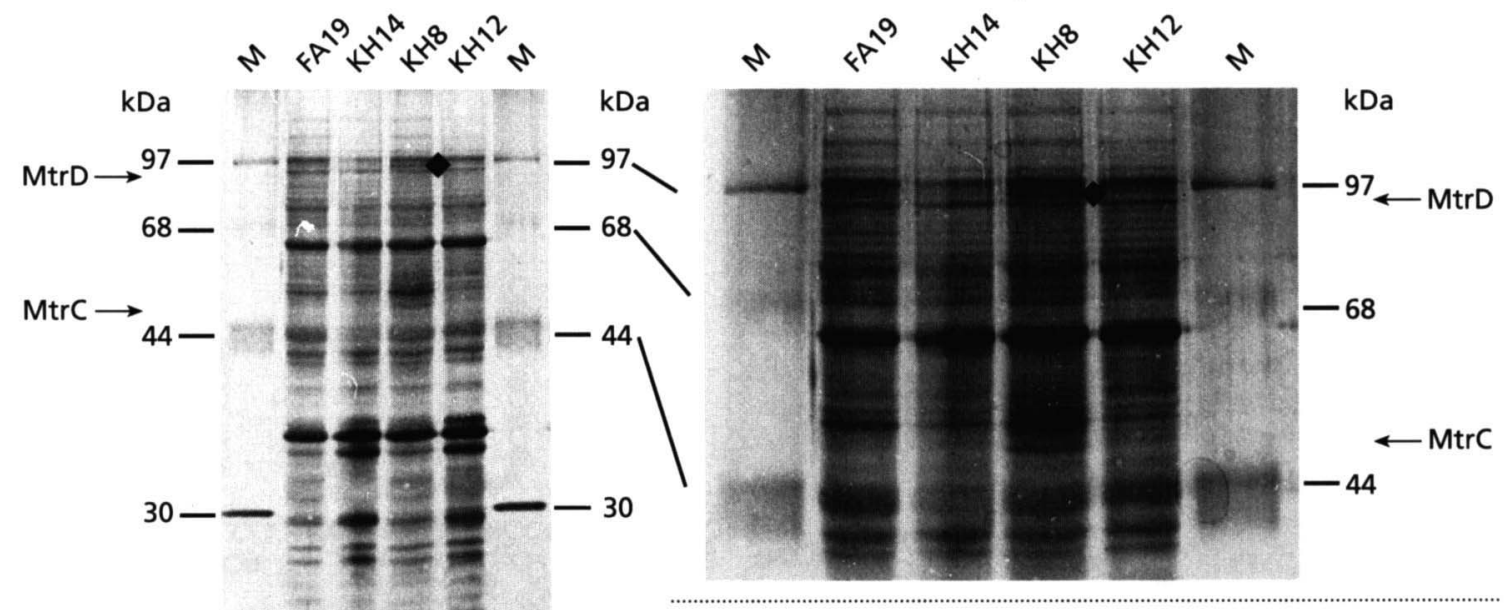

Fig. 4. SDS-PAGE profile of whole-cell lysates of strains FA19, $\mathrm{KH} 14, \mathrm{KH} 8$ and $\mathrm{KH} 12$. Whole-cell lysates of gonococcal strains were prepared, separated on $15 \%$ SDS-PAGE gels and stained sequentially with silver and Coomassie Brilliant Blue as described in Methods. The right panel shows the expanded top region of the gel in the left panel so as to enhance viewing of higher molecular mass proteins. Arrows signify putative migration of the $47 \mathrm{kDa}$ MtrC lipoprotein (Hagman et al., 1995) and MtrD. A diamond identifies the putative MtrD protein in strain KH8. Molecular mass markers (M) were from the Bio-Rad low molecular mass kit.

gene (Hagman et al., 1995) that would likely be cotranscribed with $m t r C D$. To circumvent this problem, we attempted to insertionally inactivate $m t r D$ with the nonpolar aphA-3 cassette (Ménard et al., 1993) as was done for generating an insertionally inactivated $m t r E$ gene (Delahay et al., 1997). Unfortunately, repeated attempts to do so failed, perhaps because production of the MtrE outer-membrane protein without the MtrD transporter protein is lethal.

\section{Electrophoretic analysis of gonococcal proteins}

To determine the impact of insertional inactivation of $m t r D$ on gonococcal proteins and to visualize the MtrD protein, total cellular proteins in whole-cell lysates of isogenic strains were analysed by SDS-PAGE and Western immunoblotting. When whole-cell lysates from strains FA19, KH8 [which, like strain KH15 overproduces MtrC (Hagman et al., 1995) due to a single bp deletion (mtrR-171) in a $13 \mathrm{bp}$ inverted repeat in the $m t r R$ promoter (Hagman \& Shafer, 1995)], KH12 $\left(m t r C:: K m^{\mathrm{R}}\right)$ and $\mathrm{KH} 14\left(m t r D:: K m^{\mathrm{R}}\right)$ were examined by SDS-PAGE a protein of nearly $97 \mathrm{kDa}$ appeared to be correlated with MtrD. Thus, a $\sim 97 \mathrm{kDa}$ stained band was present in strain FA19 and was present in elevated amounts in strain $\mathrm{KH} 8$ but in decreased amounts in strains KH12 and KH14 (Fig. 4). Due to the nature of the mutations in strains $\mathrm{KH} 8, \mathrm{KH} 12$ and $\mathrm{KH} 14$, and the fact that the $m t r C D E$ gene complex represents a single transcriptional unit (Hagman et al., 1995), these results suggested that the $\sim 97 \mathrm{kDa}$ staining band might contain mature MtrD among other co-migrating proteins. To determine whether MtrD migrated as a $\sim 97 \mathrm{kDa}$ protein in SDS-PAGE, an anti-MtrD peptide antiserum (see Methods) was used to probe a Western blot containing whole-cell lysates from these isogenic strains. This polyclonal antiserum and a pre-bleed serum (data not presented) reacted with at least five gonococcal proteins in the $50-80 \mathrm{kDa}$ region of the SDS-PAGE. However, only the anti-MtrD peptide antiserum specifically recognized a protein of nearly $97 \mathrm{kDa}$ in whole-cell lysates prepared from strains KH8 and FA19 but was absent in strains $\mathrm{KH} 12$ and KH14 (Fig. 5). The lower apparent molecular mass of MtrD in whole-cell lysates of strains FA19 and KH8, as judged by SDS-PAGE and Western blotting, compared to that predicted by DNA sequence analysis may reflect proteolytic processing events other than removal of the signal peptide or its electrophoretic mobility in SDS-PAGE may not accurately reflect its molecular mass.

To determine whether loss of MtrD affected the level of its companion membrane fusion protein, the level of MtrC in strains FA19, KH8, KH12 and $\mathrm{KH} 14$ was determined by Western blotting using an anti-MtrC monoclonal antibody (Fig. 5). In both the whole-cell lysate (Fig. 5) and total membrane preparations (data not presented), the MtrC protein was present in strain FA19, present in elevated levels in strain $\mathrm{KH} 8$, and absent in strain KH12. Unexpectedly, however, the level of the MtrC protein in strain $\mathrm{KH} 14$ was reduced. This was not due to reduced expression of the $m t r C$ gene, which lies immediately upstream of $m t r D$ in the same transcriptional unit (Fig. 1), because a slot-blot RNA hybridization study revealed that strains FA19 and $\mathrm{KH} 14$ contained very similar levels of $m t r C$ mRNA (Fig. 
(a)

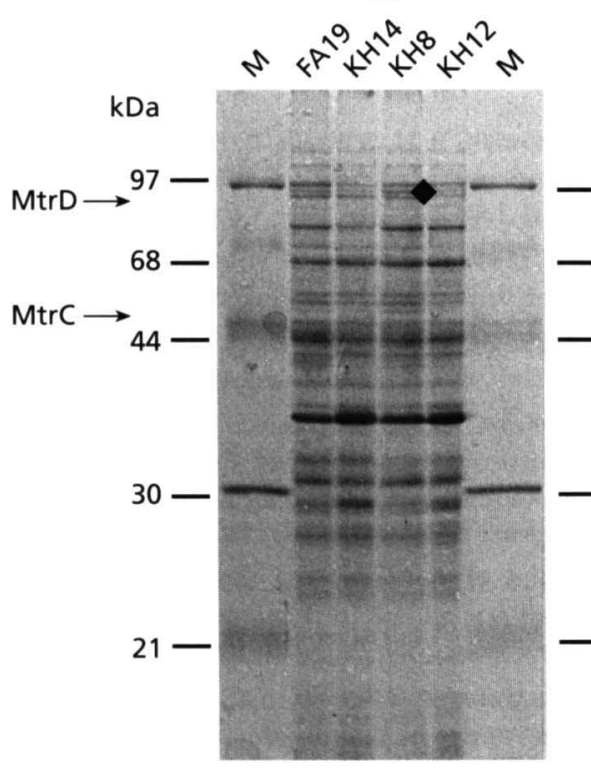

(b)

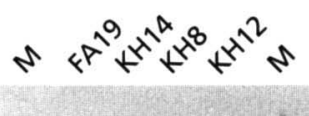

(c)

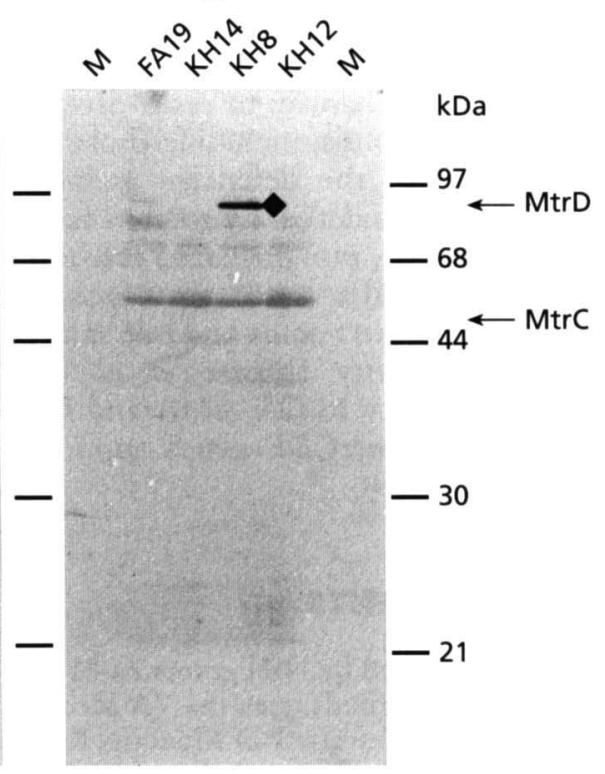

Fig. 5. Western immunoblot analysis for detection of MtrD and MtrC. Samples were treated as described in Fig. 4 legend (a), and proteins were then electrophoretically transferred to PVDF membranes and probed with an anti-MtrC monoclonal antibody (Hagman et al., 1995) (b) or anti-MtrD peptide antiserum as described in Methods (c). Arrows identify the migration of the immunoreactive MtrC and MtrD proteins, and the diamond identifies the MtrD band in the lane containing whole-cell lysates from strain KH8. Molecular mass markers were as described in Fig. 4 legend.

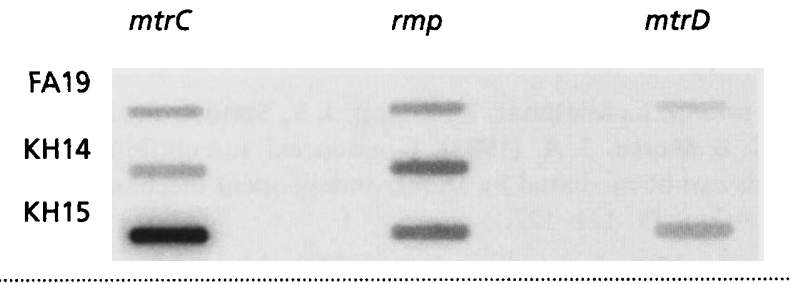

Fig. 6. Expression of the $m \operatorname{tr} C D$ genes in gonococcal strains. A phosphoimager-derived profile is shown of a slot-blot hybridization of total RNA from strains FA19, KH14 and KH15. Twenty micrograms of total RNA was hybridized with genespecific probes to detect $m t r C, m t r D$ and $r m p$ transcripts. The $m t r C D$ transcripts are elevated in strain $\mathrm{KH} 15$ due to the $m t r R$ 171 mutation. Note that while the control rmp-specific transcript was detected in all three strains, the $m t r D$ transcript was only detected in strains FA19 and KH15.

6). Thus, we propose that without the anchoring effect supplied by the cytoplasmic-membrane-bound MtrD, the MtrC membrane fusion protein is rapidly turned over.

Determination of the complete nucleotide sequence for the $m t r D$ gene allowed us to unambiguously place the MtrD protein in the RND family of bacterial cytoplasmic membrane proteins that are critical for export of antibacterial agents (Ma et al., 1994; Saier et al., 1994). Our earlier characterization of the MtrC membrane fusion protein and evidence (Hagman et al., 1995) for the existence of an OprM homologue in gonococci
(MtrE), which would form a channel in the outer membrane, indicates that the membrane organization of the $m t r$ efflux pump is similar to that proposed by $\mathrm{Ma}$ et al. (1994) for the MexA-MexB-OprM efflux pump possessed by $P$. aeruginosa. The description of the gonococcal MtrE protein and its importance in determining $\mathrm{HA}^{\mathbf{R}}$ in gonococci are described by Delahay et al. (1997). Despite the apparent structural similarities between the MtrC-MtrD-MtrE and MexA-MexBOprM efflux pumps it is important to stress that these systems likely display functional differences. Thus, the efflux pump possessed by $P$. aeruginos $a$ can apparently enhance resistance to ciprofloxacin ( $\mathrm{Li}$ et al., 1994), while the highly similar gonococcal mtr pump appears unable to modulate susceptibility to this hydrophilic antibiotic (Table 1) and other quinolone antibiotics (Shafer et al., unpublished observations). Moreover, the transcriptional repressors [MtrR for N. gonorrhoeae (Pan \& Spratt, 1994) and MexR for P. aeruginosa (Poole et al., 1996)] do not show structural similarities.

Efflux pumps presumably evolved long before the introduction of antibiotics in the clinical setting, perhaps arising from some other transport system, permitting bacteria to resist antimicrobial agents in their natural environment (Levy, 1992; Ma et al., 1994). From an ecological viewpoint, the capacity of efflux pumps, such as the $m t r C D E$-encoded system, to remove structurally diverse antimicrobial agents would provide bacteria with a growth advantage in environments containing 
multiple and structurally diverse antimicrobial agents. Since the broad substrate specificity displayed by many efflux pumps (reviewed by Ma et al., 1994) endows pathogens with a mechanism to resist diverse, multiple antimicrobial compounds, including those encountered at mucosal surfaces, the defensive activity of efflux pumps should be considered a virulence factor. During gonococcal infections, $m t r$-mediated resistance to HAs might enhance survival at mucosal surfaces, such as the rectum, where toxic fatty acids and bile salts could have anti-gonococcal activity (Morse et al., 1982). The increased susceptibility to CA, CHA and PA of strains bearing inactivated $m t r C D E$ genes supports this hypothesis.

\section{ACKNOWLEDGEMENTS}

This work was supported by NIH grants AI-21150 (W.M.S.) and AI-21236 (R.C.J.), funds from the VA Medical Research Service (W.M.S.) and University of Montana Research Grant 1642 (R.C. J.). W.M.S. is the recipient of an Associate Career Scientist Award from the VA Medical Research Service. C.E.L. was supported by a pre-doctoral fellowship from the American Society for Microbiology.

We thank D. Balding for help in the construction of $\mathrm{pBS} \Delta \mathrm{H} 3$, the staff of the Microchemical Facility of Emory University for oligonucleotide preparation, the staff of the University of Montana Molecular Biology Facility for the preparation of the MtrD peptide, L. Pucko for help in manuscript preparation and C. A. Ison for reading the manuscript prior to submission.

\section{REFERENCES}

Baker, R. F. \& Yanofsky, C. F. (1968). The periodicity of RNA polymerase initiations: a new regulatory feature of transcription. Proc Natl Acad Sci USA 60, 313-320.

Claros, M. G. \& von Heijne, G. (1994). TopPredII: an improved software for membrane protein structure predicitions. CABIOS 10, 685-696.

Delahay, R. M., Robertson, B. D., Balthazar, J. T., Shafer, W. M. \& Ison, C. A. (1997). Involvement of the gonococcal MtrE protein in the resistance of Neisseria gonorrboeae to toxic hydrophobic agents. Microbiology 143, 2127-2133.

Guymon, L. F. \& Sparling, P. F. (1975). Altered crystal violet permeability and lytic behavior in antibiotic-resistant and sensitive strains of Neisseria gonorrhoeae. J Bacteriol 124, 757-763.

Hagman, K. E. \& Shafer, W. M. (1995). Transcriptional control of the $m t r$ efflux system of Neisseria gonorrhoeae. J Bacteriol 177, $4162-4165$.

Hagman, K. E., Pan, W., Spratt, B. G., Balthazar, J. T., Judd, R. C. \& Shafer, W. M. (1995). Resistance of Neisseria gonorrhoeae to antimicrobial hydrophobic agents is modulated by the $m t r R C D E$ efflux system. Microbiology 141, 611-622.

von Heijne, G. (1989). Control of topology and mode of assembly of a polytopic membrane protein by positively charged residues. Nature 341, 456-458.

von Heijne, G. (1992). Membrane protein structure prediction: hydrophobicity analysis and the positive-inside rule. $J \mathrm{Mol}$ Biol 225, 487-494.
Judd, R. C., Strange, J. C., Pettit, R. K. \& Shafer, W. M. (1991). Identification and characterization of a conserved outer membrane protein of Neisseria gonorrhoeae. Mol Microbiol 5, 1091-1096.

Klein, J. R., Heinrich, B. H. \& Plapp, R. (1991). Molecular analysis and nucleotide sequence of the envCD operon of Escherichia coli. Mol Gen Genet 230, 230-240.

Laemmli, U. K. (1970). Cleavage of structural proteins during the assembly of the head of bacteriophage T4. Nature 227, 680-685.

Levy, S. B. (1992). Active efflux mechanisms for antimicrobial resistance. Antimicrob Agents Chemother 36, 695-703.

Li, X.-Z., Livermore, D. M. \& Nikaido, H. (1994). Role of efflux pump(s) in intrinsic resistance of Pseudomonas aeruginosa: resistance to tetracycline, chloramphenicol, and norfloxacin. Antimicrob Agents Chemother 38, 1732-1741.

Li, X.-Z., Nikaido, H. \& Poole, K. (1995). Role of MexA-MexBOprM in antibiotic efflux in Pseudomonas aeruginosa. Antimicrob Agents Chemother 39, 1948-1953.

Lucas, C. E., Hagman, K. E., Levin, J. C., Stein, D. C. \& Shafer, W. M. (1995). Importance of lipooligosaccharide structure in determining gonococcal resistance to hydrophobic antimicrobial agents resulting from the $m$ tr efflux system. Mol Microbiol 16, 1001-1009.

Ma, D., Cook, D. N., Alberti, M., Nikaido, H. \& Hearst, J. E. (1993). Molecular cloning of the acrA and acrE genes of Escherichia coli. $J$ Bacteriol 175, 6299-6313.

Ma, D., Cook, D. N., Hearst, J. E. \& Nikaido, H. (1994). Efflux pumps and drug resistance in Gram-negative bacteria. Trends Microbiol 2, 489-493.

McAllister, C. F. \& Stephens, D. S. (1993). Analysis in Neisseria meningitidis and other Neisseria species of genes homologous to the FKBP immunophilin family. Mol Microbiol 10, 13-24.

McFarland, L., Mietzner, T., Knapp, J. S., Sandstrom, E., Holmes, K. K. \& Morse, S. A. (1983). Gonococcal susceptibility to fecal lipids can be mediated by an $m t r$-independent mechanism. J Clin Microbiol 18, 121-127.

Maness, M. J. \& Sparling, P. F. (1973). Multiple antibiotic resistance due to a single mutation in Neisseria gonorrboeae. $J$ Infect Dis 128, 321-330.

Ménard, R., Sansonetti, P. J. \& Parsot, C. (1993). Nonpolar mutagenesis of the ipa genes defines IpaB, IpaC and IpaD as effectors of Shigella flexneri entry into epithelial cells. J Bacteriol 175, 5899-5906.

Morse, S. A., Lysko, P. G., McFarland, L., Knapp, J. S., Sandstrom, E., Critchlow, C. \& Holmes, K. K. (1982). Gonococcal strains from homosexual men have outer membranes with reduced permeability to hydrophobic molecules. Infect Immun 37, 432-438.

Pan, W. \& Spratt, B. G. (1994). Regulation of the permeability of the gonococcal cell envelope by the $m$ tr system. Mol Microbiol 11, 769-775.

Poole, K., Heinrichs, D. E. \& Neshat, S. (1993a). Cloning and sequence analysis of an EnvCD homologue in Pseudomonas aeruginosa: regulation by iron and possible involvement in secretion of siderophore pyoverdine. Mol Microbiol 10, 529-544.

Poole, K., Krebes, K., McNally, C. \& S. Neshat. (1993b). Multiple antibiotic resistance in Pseudomonas aeruginosa: evidence for involvement of an efflux operon. J Bacteriol 175, 7363-7372.

Poole, K., Tetro, K., Zhao, Q., Neshat, S., Heinrichs, D. E. \& Bianco, N. (1996). Expression of the multidrug resistance operon mexAmexB-oprM in Pseudomonas aeruginosa: mexR encodes a 
regulator of operon expression. Antimicrob Agents Chemother 40, 2021-2028.

Prentki, P. \& Krisch, H. M. (1984). In vitro insertional mutagenesis with a selectable DNA fragment. Gene 29, 303-313.

Saier, M. H., Jr, Tam, R., Reizer, A. \& Reizer, J. (1994). Two novel families of bacterial membrane proteins concerned with nodulation, cell division and transport. Mol Microbiol 11, 841-847.

Shafer, W. M., Guymon, L. F., Lind, I. \& Sparling, P. F. (1984). Identification of an envelope mutation $(e n v-10)$ resulting in increased antibiotic susceptibility and pyocin resistance in a clinical isolate of Neisseria gonorrboeae. Antimicrob Agents Chemother 25, 767-769.

Sparling, P. F., Sarubbi, F. A. \& Blackman, E. (1975). Inheritance of low-level resistance to penicillin, tetracycline, and chloramphenicol in Neisseria gonorrhoeae. J Bacteriol 124, 740-749.

Received 5 December 1996; revised 6 March 1997; accepted 10 March 1997. 